\title{
Guidelines for research: requirements and challenges
}

\author{
Silvana Galderisi \\ From $1^{\text {st }}$ International Congress on Neurobiology and Clinical Psychopharmacology and European \\ Psychiatric Association Conference on Treatment Guidance \\ Thessaloniki, Greece. 19-22 November 2009
}

Research aimed to foster the understanding of causes and consequences of mental disorders and to improve their outcome should be a priority in the agenda of clinicians, researchers and health policy makers. Published guidelines for research in Psychiatry have highlighted main requirements, which will be summarized and discussed in the presentation. Research in Psychiatry has to conform to ethical principles and rigorous scientific standards. Openness and transparency should characterize the management of eventual conflicts of interests; professional integrity and independence from external pressure and influence must represent an obligation. In addition to human research ethical principles, research in Psychiatry involves unique aspects relevant to the nature of mental disorders. Awareness of general and disorder specific ethical aspects has to be promoted among trainees and researchers and adequate procedures to deal with these aspects must be implemented. Studies should address clinically relevant questions, select the least vulnerable individuals to adequately answer the study questions; the design and methods should minimize risks and threats for patients and be adequate to address the study questions. Care must be taken to ensure privacy and patients' freedom to leave the experimental protocol at any time without negative consequences for their clinical care. Translating these principles into everyday research activities is the present challenge for researchers in Psychiatry and for all those caring for the progress of the discipline. National and international educational programmes for trainees in Psychiatry, for investigators conducting research involving people with mental disorders, and for members of institutional review boards should be developed.

Department of Psychiatry, University of Naples SUN, Naples, Italy
Published: 22 April 2010

doi:10.1186/1744-859X-9-S1-S54

Cite this article as: Galderisi: Guidelines for research: requirements and challenges. Annals of General Psychiatry 2010 9(Suppl 1):S54.
Submit your next manuscript to BioMed Central and take full advantage of:

- Convenient online submission

- Thorough peer review

- No space constraints or color figure charges

- Immediate publication on acceptance

- Inclusion in PubMed, CAS, Scopus and Google Scholar

- Research which is freely available for redistribution

Submit your manuscript at www.biomedcentral.com/submit
() Biomed Central 